\title{
Comparison of a Novel Curvilinear Approach to Conventional Rectilinear Approach for Prostate Seed Implant
}

\author{
T. K. Podder \\ Thomas Jefferson University and Hospitals
}

A. P. Dicker

Thomas Jefferson University and Hospitals

Y. Yu

Thomas Jefferson University and Hospitals

Follow this and additional works at: https://jdc.jefferson.edu/bodinejournal

Part of the Oncology Commons

Let us know how access to this document benefits you

\section{Recommended Citation}

Podder, T. K.; Dicker, A. P.; and Yu, Y. (2010) "Comparison of a Novel Curvilinear Approach to Conventional Rectilinear Approach for Prostate Seed Implant," Bodine Journal: Vol. 3 : Iss. 1 , Article 16.

DOI: https://doi.org/10.29046/TBJ.003.1.015

Available at: https://jdc.jefferson.edu/bodinejournal/vol3/iss1/16

This Article is brought to you for free and open access by the Jefferson Digital Commons. The Jefferson Digital Commons is a service of Thomas Jefferson University's Center for Teaching and Learning (CTL). The Commons is a showcase for Jefferson books and journals, peer-reviewed scholarly publications, unique historical collections from the University archives, and teaching tools. The Jefferson Digital Commons allows researchers and interested readers anywhere in the world to learn about and keep up to date with Jefferson scholarship. This article has been accepted for inclusion in Bodine Journal by an authorized administrator of the Jefferson Digital Commons. For more information, please contact: JeffersonDigitalCommons@jefferson.edu. 


\section{Comparison of a Novel Curvilinear Approach to Conventional Rectilinear Approach for Prostate Seed Implant}

Podder, T.K., Dicker, A.P. , Yu, Y.

Department of Radiation Oncology, Thomas Jefferson University and Hospitals, Philadelphia, PA

\section{Purpose}

To evaluate dosimetric benefit of curvilinear distribution of seeds for low-dose-rate (LDR) prostate brachytherapy with I-125 isotopes.

\section{Method and Materials}

In this study, ten LDR prostate brachytherapy cases used clinically were randomly selected as reference rectilinear cases. These cases were planned intra-operatively with VariSeed version 7.1 using I-125 seeds (STM-1251 model). All the cases were replanned by using curved-needles keeping the same individual seed's activity and volume receiving $100 \%$ of prescribed dose $145 \mathrm{~Gy}$ (V100). Various parameters such as number of total needle, number of total seeds (or total activity), and dose coverage of prostate (D90, V150, V200), urethra (D30, D10) and rectum (D5, V100 in cc) were compared.

\section{Results}

Average reductions in required number of needles and seeds (or activity) were $30.1 \%$ and $10.6 \%$, respectively for curvilinear approach. In case of prostate, average D90 reduced by 7.9\% (203.9Gy in rectilinear, 187.5Gy in curvilinear); average V150 and V200 coverage reduced by $17.9 \%$ (66.4\% in curvilinear) and $32.6 \%(29.4 \%$ in curvilinear), respectively. For urethra, average D30 reduced by $10 \%$ (from $205.3 \mathrm{~Gy}$ in rectilinear to $184.7 \mathrm{~Gy}$ in curvilinear) and D10 reduced by $9.4 \%$ (from 210.8 Gy in rectilinear to 190.0 Gy in curvilinear). In case of rectum, average reduction in V100 was $71.6 \%$ (from $0.91 \mathrm{cc}$ in rectilinear to $0.21 \mathrm{cc}$ in curvilinear) and reduction in D5 was $17.7 \%$ (from $160.4 \mathrm{~Gy}$ in rectilinear to $131.2 \mathrm{~Gy}$ in curvilinear).

\section{Conclusion}

We observed considerable reduction in all studied parameters for curvilinear approach. Prostate dose homogeneity (V150, V200) improved while urethral dose is reduced, which will potentially result in better treatment. Large reduction in rectal dose would potentially reduce rectal toxicity and complications. Reduction in number of needles would minimize edema and thereby would improve accuracy of seed delivery and total dose distribution. This study indicates that the curvilinear approach is dosimetrically superior to conventional rectilinear technique. 